\title{
UM MODELO DE GESTÃO DO RELACIONAMENTO ENTRE OS CIDADÃOS E A ADMINISTRAÇÃO PÚBLICA
}

\author{
Rodrigo Diniz Lara* \\ rdinizl@ibes.com.br \\ Marlusa de Sevilha Gosling** \\ mg.ufmg@gmail.com
* Secretaria de Estado de Planejamento e Gestão de Minas Gerais - Belo Horizonte, BH / Brasil \\ **Universidade Federal de Minas Gerais - Belo Horizonte, BH / Brasil
}

http://dx.doi.org/10.1590/1413-2311.0522015.59196

Recebido em 07/10/2015

Aprovado em 10/06/2016

Disponibilizado em 31/08/2016

Avaliado pelo sistema "double blind review"

Revista Eletrônica de Administração

Editora-chefe: Aurora Zen

ISSN 1413-2311 (versão "on line")

Editada pela Escola de Administração da Universidade Federal do Rio Grande do Sul.

Periodicidade: Quadrimestral

Sistema requerido: Adobe Acrobat Reader

\section{RESUMO}

A evolução do movimento da Nova Gestão Pública aumentou a pressão sobre as burocracias estatais no sentido de analisar os cidadãos como clientes. Nos últimos anos, as medidas implementadas pelos governos para tornar a administração mais focada no cidadão contemplaram ações pontuais e não integradas de melhoria na qualidade, na eficiência e na acessibilidade do atendimento aos cidadãos e na prestação dos serviços públicos. Nesse contexto, o objetivo do artigo é propor um modelo de gestão do relacionamento entre os cidadãos e a administração pública no processo de prestação de serviços públicos baseado em fatores do Marketing de Relacionamento, que, na percepção dos gestores públicos e dos próprios cidadãos, são considerados essenciais. O método adotado consistiu em uma pesquisa exploratório-descritiva, com uma abordagem mista. Primeiramente, uma fase qualitativa conduziu entrevistas com 11 gestores públicos responsáveis pelos canais de atendimento ao cidadão do Governo do Estado de Minas Gerais para identificar os fatores essenciais na percepção desse público. Com base na metodologia de Grounded Theory e na análise de conteúdo suportado pelo software Atlas TI identificou-se a percepção dos gestores responsáveis pelos canais de atendimento do governo mineiro os seguintes fatores do modelo: estratégia; gestão da informação; integração multicanal; programas de relacionamento; estrutura; tecnologia da informação e avaliação de desempenho. Posteriormente, durante a fase quantitativa, 354 cidadãos que utilizaram uma unidade de atendimento do governo mineiro preencheram um questionário da pesquisa. Na visão dos cidadãos, a partir de uma Análise Fatorial Exploratória, identificamos os seguintes: acompanhamento da prestação de 


\title{
UM MODELO DE GESTÃO DO RELACIONAMENTO ENTRE OS CIDADÃOS E A
} ADMINISTRAÇÃO PÚBLICA

serviço; consolidação dos canais de atendimento; forma de atendimento; recompensas e diversificação dos canais de atendimento.

Palavras-chave: marketing de relacionamento; cidadão-cliente; gestão de relacionamento com os cidadãos; CzRM.

\section{A MANAGEMENT MODEL OF THE RELATIONSHIP BETWEEN CITIZENS AND PUBLIC ADMINISTRATION}

\begin{abstract}
The evolution of the movement known as New Public Management has increased pressure on state bureaucracies to analyze the citizens as customers. In recent years, the measures implemented by governments to make the administration more focused on the citizens contemplated specific and non-integrated actions to improve quality, efficiency and accessibility of the services offered. In this context, the article aims to propose a management model of the relationship between citizens and the public administration in the public service based on factors of Relationship Marketing process that, in the perception of public officials and the general public, are considered essential. The method used consisted of an exploratorydescriptive research with a mixed approach. First, a qualitative phase was consisted of interviews with 11 managers of public service responsible for the different channels of providing services to the citizens of the State of Minas Gerais, with the objective of identifying key factors in their perception. Based on the methodology of Grounded Theory and on content analysis supported by Atlas TI the following key factors were identified as the ones to be included in the model: strategy; information management; multichannel integration; relationship programs; structure; information technology and performance evaluation. Later, during the quantitative phase, 354 citizens who used a service unit of the government completed a questionnaire survey. In the citizens view, from an Exploratory Factor Analysis, the following important dimensions to enhance their relationship with the government were identified: Monitoring of service; Consolidation of service channels; Employees; Way of attendance; Rewards; and Diversification of the service channels.
\end{abstract}

Keywords: Marketing Relationship; Citizen-client; Citizens Relationship Management; CzRM.

\section{UN MODELO DE GESTIÓN DE LA RELACIÓN ENTRE LOS CIUDADANOS Y LA ADMINISTRAÇÃO PÚBLICA}

\section{RESUMEN}

La evolución del movimiento de la Nueva Gestión Pública aumentó la presión sobre las burocracias estatales con el fin de analizar los ciudadanos como clientes. En los últimos años, las medidas puestas en marcha por los gobiernos para hacer la administración más centrado en el ciudadano acciones contempladas específica y no una parte de la mejora de la calidad, eficiencia y accesibilidad de los servicios a los ciudadanos y la prestación de servicios públicos. En este contexto, el objetivo del artículo es proponer un modelo de gestión de las relaciones entre los ciudadanos y el gobierno en la prestación de los servicios públicos basados en factores de marketing relacional, que, en la percepción de los funcionarios públicos y el público en general, se consideran esenciales. El método utilizado consistió en un estudio exploratorio-descriptivo con un enfoque mixto. En primer lugar, una fase cualitativa llevó a cabo entrevistas con 11 directores responsables de los canales de servicio público a los ciudadanos del Estado de Minas Gerais para identificar los factores clave en la percepción de 


\section{Rodrigo Diniz Lara \& Marlusa de Sevilha Gosling}

ese público. Con base en la metodología de la teoría fundamentada y análisis de contenido apoyado por el software de TI Atlas identificó aa la percepción de los directivos responsables de los canales de atención del gobierno estatal los siguientes factores de modelo: estrategia; gestión de la información; integración multicanal; programas de relación; estructura; tecnología de la información y la evaluación del desempeño. Más tarde, durante la fase cuantitativa, 354 ciudadanos que utilizan una unidad de cuidados gobierno minero llenaron un cuestionario. En opinión de los ciudadanos, a partir de un análisis factorial exploratorio, se identificaron los siguientes: seguimiento de la prestación de servicios; consolidación de los canales de servicio; forma de servicio; recompensas y diversificación de los canales de servicio.

Palabras Clabe: Marketing Relacional; Ciudadano-cliente; Gestión de Relaciones con los Ciudadanos; CzRM

\section{INTRODUÇÃO}

A Reforma do Estado, iniciada no Brasil na década de 90, teve como documento norteador o Plano Diretor da Reforma do Estado publicado em 1995. Ela apresentou como uma das suas principais diretrizes possibilitar que a administração pública se tornasse mais eficiente e oferecesse aos cidadãos serviços públicos com mais qualidade, por meio da otimização dos seus processos de prestação, desburocratizando-os e estabelecendo indicadores de desempenho e satisfação do cidadão (BRASIL, 1995).

Abrucio (1997) relata que essa reforma do Estado brasileiro, também denominada Nova Gestão Pública, teve como uma das suas fases o Consumerism, que tem como pressupostos a efetividade e a qualidade dos serviços públicos, tendo o cidadão como cliente/consumidor. A evolução do movimento da Nova Gestão Pública aumentou a pressão sobre as burocracias estatais com o intuito de analisar os cidadãos como clientes da máquina pública (VIGODA, 2002).

A utilização das novas tecnologias da informação e comunicação na prestação dos serviços públicos, também denominada Governo Eletrônico (e-gov), deu novo impulso à Nova Gestão Pública no final dos anos 90. O e-gov tem facilitado o acesso às informações e serviços do setor público a cidadãos, empresas e servidores e tem aumentado a velocidade e a eficiência dos processos, gerando melhoria da qualidade dos serviços e redução de custos (DEMO E PONTE, 2008; KANNABIRAN, XAVIER E ANANTHARAAJ, 2004; SCHELLONG, 2008).

Nos últimos anos, as medidas implementadas pelos governos para tornar a administração mais focada no cidadão contemplaram ações pontuais e não integradas de 


\section{UM MODELO DE GESTÃO DO RELACIONAMENTO ENTRE OS CIDADÃOS E A ADMINISTRAÇÃO PÚBLICA}

melhoria na qualidade, na eficiência e na acessibilidade da prestação dos serviços públicos (SCHELLONG, 2008). São exemplos dessa questão a criação de vários sítios governamentais, de centrais de atendimento ao cidadão, de call centers e, mais recentemente, de redes sociais para comunicação com o cidadão. O governo estadual mineiro é um exemplo disso, já que possui o Portal mg.gov.br, a Central de Atendimento Telefônica (LigMinas 155) e as Unidades de Atendimento Integradas (UAIs) presenciais.

Porém, tais canais não possuem uma perspectiva integrada, o que dificulta uma visão única do cidadão e de suas demandas. Estas ações, apesar de representarem um grande avanço em relação às estruturas tradicionais de prestação de serviços da administração pública, possuem o viés de focar apenas as transações individuais com o cidadão, sem a perspectiva de continuidade e integração buscada pelo marketing de relacionamento (MR), a exemplo do setor privado.

Nesse contexto, a Gestão do Relacionamento com os Cidadãos, traduzido do inglês Citizen Relationship Management (CzRM), adaptado do Customer Relationship Management (CRM) da área privada, é discutido por autores como Kannabiran, Xavier e Anantharaaj (2004) e Schellong (2008) para promover a melhoria dos serviços públicos e a aproximação dos gestores públicos às necessidades do cidadão, por meio da implementação de uma visão sistêmica e consistente dos relacionamentos entre governo e cidadãos no tocante à prestação de serviços públicos.

Neste sentido, o artigo trabalha com a premissa de que existem conceitos e metodologias do marketing de relacionamento que podem ser transportados do setor privado e aplicados ao setor público de maneira a incrementar o relacionamento entre governo e cidadãos. Porém, uma vez que organizações do setor público e do setor privado possuem diferenças, que se iniciam pela própria natureza das suas atribuições, estes conceitos devem ser aplicados de forma criteriosa.

Diante do exposto, o problema a ser pesquisado se refere à seguinte pergunta central: "Quais fatores essenciais do Marketing de Relacionamento, na percepção dos gestores públicos e dos cidadãos, podem ser utilizados na construção de um modelo de gestão do relacionamento entre os cidadãos e a administração pública?”.

O objetivo é propor um modelo de gestão de relacionamento entre os cidadãos e a administração pública a partir dos modelos conceituais presentes na literatura de implementação de CRM e também a partir da experiência de gestores públicos responsáveis pela gestão de canais de atendimento ao cidadão. Há que se considerar, além disso, a 


\section{Rodrigo Diniz Lara \& Marlusa de Sevilha Gosling}

percepção dos cidadãos que utilizam esses canais, no caso dessa pesquisa, uma Unidade de Atendimento Integrado - UAI.

\section{REFERENCIAL TEÓRICO}

\subsection{Reforma do Estado: a nova Administração Pública}

As reformas do Estado surgiram em um contexto de crise econômica mundial iniciada na década de 70 do século passado (ABRUCIO, 1997). Entre os fatores destacados como motivadores pela busca da Reforma do Estado está a ineficiência na prestação de serviços públicos e o descolamento das necessidades dos cidadãos (BARZELAY, 2000; OSBORNE E GAEBLER, 1992).

Nesse contexto de instabilidade, algumas práticas da iniciativa privada ganharam evidência na administração pública em todas as esferas de governo (HOOD, 1995; SECCHI, 2009). Essa fase recebeu alguns nomes na literatura como New Public Management (NPM), Nova Administração Pública (PAES DE PAULA, 2005; BARZELAY, 2000) ou Nova Gestão Pública (SECCHI, 2009). A Nova Gestão Pública foi caracterizada por alguns modelos de administração. Alguns modelos destacados na literatura são o Gerencialismo (Managerialism), o Consumerism e o Public Service Orientation (PSO).

O Gerencialismo (Managerialism) ou modelo gerencial puro teve como principal bandeira a preocupação com a questão financeira, já que era premissa do modelo a redução dos gastos públicos tendo em vista um contexto de crise fiscal (ABRUCIO, 1997). Para isso foi incorporado fortemente o conceito de aumentar a eficiência e eficácia administrativa do Estado (ABRUCIO, 1997; BARZELAY, 2000; BRESSER-PEREIRA, 2006; SECCHI, 2009). Vale destacar que dentro dessa visão do Gerencialismo de redução dos gastos e a obtenção de maiores retornos, ou seja, aumentar a produtividade e a eficiência do setor público, o cidadão assume um papel de mero contribuinte para manter a máquina pública (ABRUCIO, 1997).

O Consumerism tenta corrigir o desequilíbrio de poder que existe entre aqueles que produzem bens e serviços e aqueles para os quais eles são fornecidos. Abrucio (1997) aponta como características desse novo modelo a preocupação com a qualidade dos serviços públicos e a prioridade às demandas do cliente/consumidor na administração pública. Osborne e Gaebler (1992) destacam que um dos mandamentos da nova administração pública é o 


\section{UM MODELO DE GESTÃO DO RELACIONAMENTO ENTRE OS CIDADÃOS E A ADMINISTRAÇÃO PÚBLICA}

governo orientado ao cliente no qual ele deve substituir a perspectiva de atender as necessidades internas pela lógica de atenção às necessidades dos clientes/cidadãos.

Prata (1998) relata que não existe dúvida de que a inserção do conceito de cliente representou uma alteração importante e positiva na cultura organizacional do setor público. Vigoda (2002) expõe que a evolução do movimento da Nova Gestão Pública aumentou a pressão sobre as burocracias estatais no sentido de tornar-se mais sensível às demandas dos cidadãos como clientes. Essa questão está relacionada com a capacidade de resposta do governo e baseia-se na visão de mercado de um melhor serviço para os cidadãos como clientes.

A adoção do Consumerism, contudo, levanta algumas questões relevantes. A primeira delas é “quem é o cliente no setor público?”, questão que é mais bem equacionada nas empresas privadas, mas que na esfera pública não tem consenso (PRATA, 1998).

Prata (1998), ao avaliar a questão de uma forma mais ampla, aborda o dilema de contrabalançar os interesses do contribuinte, aquele que efetivamente fornece os recursos para que os serviços sejam prestados, com as reivindicações dos beneficiários diretos destes serviços. A autora expõe que nem sempre aquele que recebe serviços públicos é realmente um contribuinte; ou ainda, aqueles que mais contribuem com impostos são geralmente os que menos necessitam dos serviços públicos oferecidos individualmente, mesmo que também precisem daqueles prestados de forma coletiva, como segurança e construção de estradas.

Ao se referir aos indivíduos, Bresser-Pereira, em seus trabalhos, faz uso indistinto dos termos "cidadãos-clientes", "clientes-cidadãos", somente "clientes" ou, raras vezes, “cidadãos” (PECI, PIERANTI E RODRIGUES, 2008 ). No intuito de esclarecer o conceito, Bresser-Pereira (1999:08) afirma:

Pode-se descentralizar, controlar por resultados, incentivar a competição administrada, colocar o foco no cliente, mas a descentralização envolve o controle democrático, os resultados desejados devem ser decididos politicamente, quase mercados não são mercados, o cliente não é apenas cliente mas um cliente-cidadão revestido de poderes que vão além dos direitos do cliente ou do consumidor.

Vigoda (2002) relata que, em essência, a motivação para atender as demandas levantadas pelos cidadãos é equivalente a satisfazer as necessidades de um cliente regular em um supermercado de bairro. De acordo com este ponto de vista, a capacidade de resposta na arena pública está intimamente em conformidade com as declarações de negócios, tais como 


\section{Rodrigo Diniz Lara \& Marlusa de Sevilha Gosling}

"o cliente tem sempre razão" e "nunca discutir com as necessidades dos clientes", que são frases memorizadas pelos vendedores no primeiro dia de trabalho.

$O$ Consumerism, apesar de promover a gestão do relacionamento com clientes na arena pública, promove um relacionamento unidirecional no qual os cidadãos são veladamente encorajados a permanecer clientes passivos do governo (VIGODA, 2002). Esse modelo pode ser criticado por não fazer o suficiente para encorajar e promover a ideia de colaboração ou parceria entre os cidadãos e o governo e por não incentivar a discussão desses temas no pensamento gerencial moderno.

Abrucio (1997) relata que o Public Service Orientation (PSO) é uma corrente relativamente nova que não possui as suas diretrizes totalmente fechadas. O PSO se caracteriza mais como uma tendência que procura identificar novos pontos e discutir a validade das bases anteriores (gerencialismo e consumerism). O PSO procura incorporar em sua discussão conceitos como accountability, transparência, participação política, equidade e justiça, pontos que eram pouco discutidos no modelo gerencial.

Vigoda (2002) destaca que a Nova Gestão Pública envolve uma tensão inerente entre a melhor capacidade de resposta aos cidadãos como clientes e a colaboração eficaz com eles como parceiro. Enquanto a capacidade de resposta é vista principalmente como uma reação passiva e unidirecional para as necessidades da população, a colaboração exerce um papel mais ativo e representa um ato bidirecional de participação entre o governo e o cidadão. Em suma, o PSO trabalha o conceito de cidadão como um parceiro da administração pública.

\subsection{Gestão de Relacionamento com o Cliente}

Os especialistas em marketing têm estudando a natureza e o alcance do marketing de relacionamento e desenvolvimento de conceituações sobre o valor das relações de cooperação e de colaboração entre os diversos agentes na criação e entrega de cliente valor (PARVATIYAR E SHETH, 2000). Nesse sentido, para implementar esse aprimoramento do relacionamento entre organizações e clientes, alguns conceitos, princípios e modelos teóricos devem ser entendidos.

Gummenson (2005) relata que a grande parte das referências não apresenta definições sobre os termos de Marketing de Relacionamento (MR) e CRM, o que dificulta o entendimento pelos leitores. Gummenson (2005) em seu conceito de MR apresenta três palavras chaves: relacionamentos, redes e interações. Parvatiyar e Sheth (2000) relatam que o 


\section{UM MODELO DE GESTÃO DO RELACIONAMENTO ENTRE OS CIDADÃOS E A ADMINISTRAÇÃO PÚBLICA}

tema central da maioria dos conceitos e perspectivas de marketing de relacionamento está focado nas relações de cooperação e colaboração entre as empresas e seus clientes e/ou atores do marketing.

Outra confusão presente na literatura é a diferença entre os termos MR e CRM. Demo e Ponte (2008) consideram tais conceitos semelhantes. Payne (2005) já possui uma definição específica para CRM:

abordagem estratégica preocupada com a criação de um valor maior para as partes interessadas por meio do desenvolvimento de relações adequadas com os principais clientes e segmentos de clientes. CRM une o potencial da TI e as estratégias de marketing de relacionamento para oferecer lucros e relacionamento de longo prazo. CRM oferece melhores oportunidades para usar dados e informações para compreender os clientes e implementar melhores estratégias de marketing de relacionamento. Isto requer uma integração multifuncional de pessoas, operações, processos e recursos de marketing que é proporcionada por meio da informação, tecnologia e aplicações.

Esse artigo trabalha com a conceituação de CRM na perspectiva em que ele é considerado uma abordagem que procura projetar uma organização centrada no cliente para manter e otimizar o relacionamento com eles, adotando uma abordagem do marketing de relacionamento alinhada com as tecnologias da informação.

\subsubsection{Modelos para implementação de CRM}

A abordagem multifuncional do marketing de relacionamento, que nas grandes organizações pretende focar potencialmente as relações com milhões de clientes individuais simultaneamente, demanda um modelo intencional e sistemático para implementar o CRM (PAYNE E FROW, 2005; SIGALA, 2005). Existem na literatura modelos teóricos que propõem o planejamento, implantação e o acompanhamento da estratégia de CRM. Esse artigo estudou cinco modelos teóricos:

1) Um modelo para Gestão de Relacionamento com o Cliente (WINER, 2001);

2) Modelo conceitual de estratégia de CRM (PAYNE E FROW, 2005);

3) Modelo para medição da implantação do CRM (SIN, TSE E YIM, 2005);

4) Modelo integrado para implementação do CRM (SIGALA, 2005);

5) Fatores críticos de sucesso para implementar a estratégia de CRM (MENDOZA ET AL., 2006).

É possível identificar a convergência entre vários componentes e atividades desses modelos estudados. Porém, não existe um modelo que contemple todas as questões abordadas 


\section{Rodrigo Diniz Lara \& Marlusa de Sevilha Gosling}

por todos os cinco, apesar do modelo de Payne e Frow (2005) aproximar-se de uma abordagem mais completa. É possível identificar sete componentes principais a partir da análise dos mesmos: Estratégia; Gestão da Informação; Programas de Relacionamento; Integração Multicanal; Tecnologia da Informação; Estrutura Organizacional; e Avaliação de Desempenho.

Tendo em vista as considerações acima, propõe-se um Modelo Unificado de Implantação de CRM a partir dos cinco modelos teóricos contemplando os componentes e fatores identificados nos mesmos (Figura 1).

Figura 1 - Modelo Unificado de Implantação de CRM

\section{Gestão de Relacionamento com os Cidadãos - Citizen Relationship Management (CzRM)}

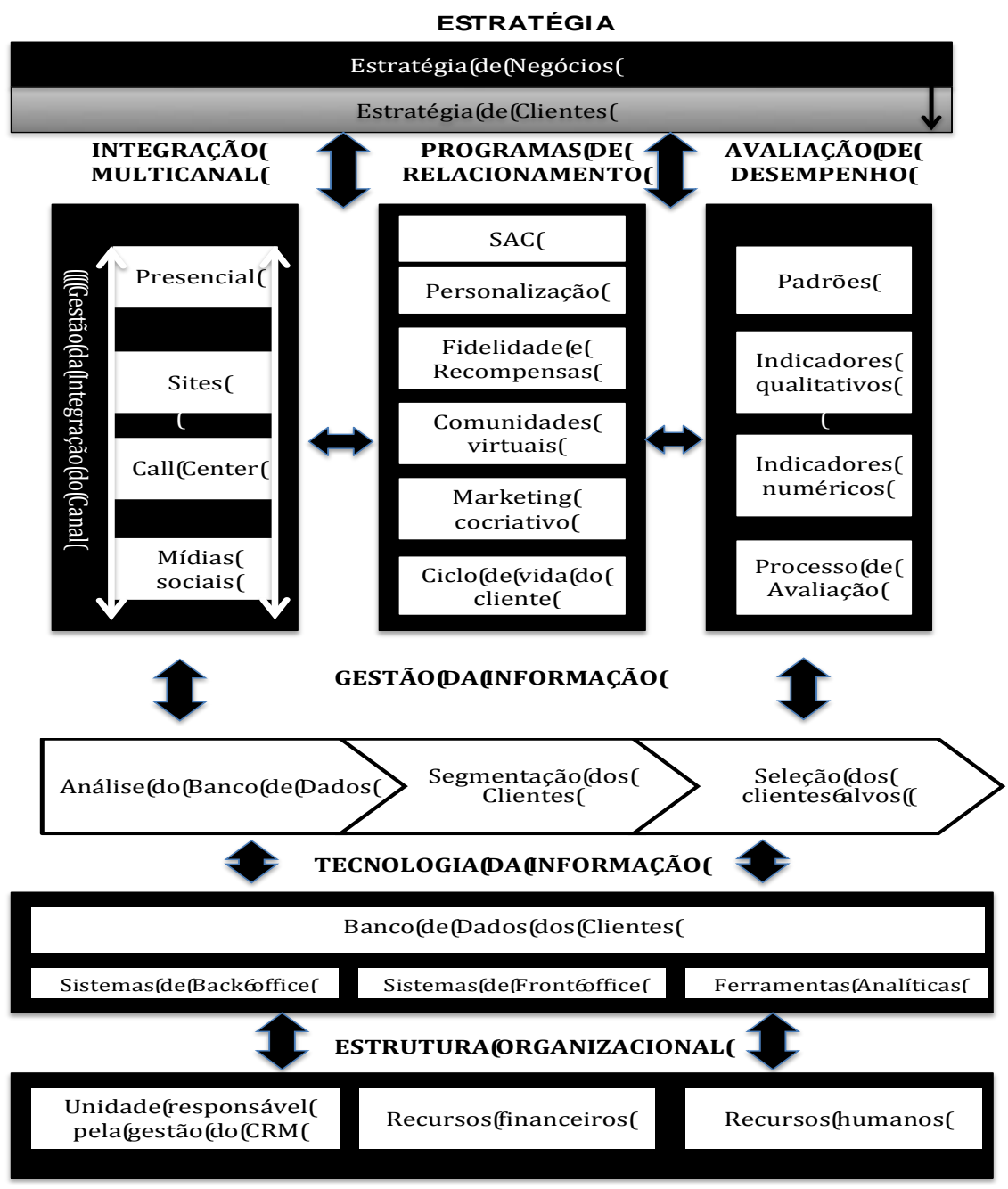

Fonte: Elaborada pelos autores, 2014

O Governo Eletrônico em muitos países atualmente tem como objetivo alcançar a eficiência na criação e entrega de serviços ao cidadão. Portanto, a maioria dos governos REAd | Porto Alegre - Edição 84 - Nº 2 - Maio / Agosto 2016 - p. 333- 362 


\section{UM MODELO DE GESTÃO DO RELACIONAMENTO ENTRE OS CIDADÃOS E A ADMINISTRAÇÃO PÚBLICA}

começa com a automação para minimização de custos e implantação de uma efetiva governança e uma administração eficiente. Os governos costumam usar múltiplos canais para oferecer seus serviços e desenvolver capacidades de trabalhar em rede com diferentes departamentos para prestar um serviço contínuo e personalizado aos seus cidadãos (KANNABIRAN, XAVIER E ANANTHARAAJ, 2004).

Com o intuito de implementar essas premissas de multicanal e atendimento personalizado, surge o conceito de Citizen Relationship Management (CzRM) ou Gestão de Relacionamento com o Cidadão com a essência de mudar as organizações de uma estrutura burocrática para a filosofia centrada no cidadão (KANNABIRAN, XAVIER E ANANTHARAAJ, 2004; SCHELLONG E LANGENBERG, 2007).

Os principais objetivos da implementação do CzRM são aumentar a satisfação dos cidadãos com o serviço público, por meio da diminuição de prazos, facilitação do acesso aos serviços públicos e execução confiável dos mesmos; identificar e atender às necessidades dos cidadãos por meio de um serviços personalizados; melhorar a qualidade das informações para o planejamento e execução dos serviços públicos; melhorar a qualidade do gasto público por meio da eficiência, diminuição do volume de contatos pessoais, melhoria do planejamento e do dimensionamento dos serviços, melhoria de processos; e estabelecer uma relação mais intensa, colaborativa e eficiente com cidadãos e empresas (YAMASHITA, 2006; KANNABIRAN, XAVIER E ANANTHARAAJ, 2004; SCHELLONG, 2008).

O primeiro item a ser trabalhado pelo CzRM é a estratégia multicanal a partir de uma visão $360^{\circ}$ do cidadão e orientada para as suas necessidades e não para as necessidades da organização. Os serviços prestados aos cidadãos devem ser fornecidos em soluções integradas como sítios, call-centers ou centrais de atendimento ao cidadão. Para facilitar a estratégia multicanal, é necessário que exista uma consolidação inicial entre os tipos de canais, como um portal, número de telefone único ou uma central de atendimento para que o cidadão possa entrar em contato. (SAREMI, 2009).

No Brasil, a consolidação do modelo de centrais de atendimento integrado nos governos estaduais apresenta-se como uma das principais práticas de atendimento ao cidadão. Entre os exemplos podemos citar: SAC (Serviço de Atendimento ao Cidadão), do estado da Bahia; Poupatempo, do estado de São Paulo; Vapt Vupt, do estado de Goiás; OCA (Organização de Centrais de Atendimento) do estado do Acre; e o modelo mineiro com as Unidades de Atendimento Integrado (UAI). Saremi (2009) destaca que, dentre as vantagens principais da estratégia multicanal, está a possibilidade das pessoas acessarem serviços 


\section{Rodrigo Diniz Lara \& Marlusa de Sevilha Gosling}

públicos e informações de qualquer lugar ganhando tempo e a possibilidade do governo conhecer melhor o cidadão e direcioná-lo para um canal com um custo menor.

O CzRM procura fornecer a informação certa para as pessoas certas no momento certo e da maneira correta. Por meio do CzRM, as administrações públicas têm uma oportunidade ímpar para acessar e manipular dados para obter uma imagem precisa do comportamento e exigências do cidadão (KANNABIRAN, XAVIER E ANANTHARAAJ, 2004). O CzRM fornece uma visão de cada cidadão dentro de sua relação com o governo, com o intuito de aumentar a excelência dos serviços e informações prestadas e, dessa forma, construir e fortalecer os laços e a cooperação entre o governo, os seus cidadãos e as partes interessadas (SCHELLONG, 2008).

Outro componente necessário para aprimorar o CzRM é a instituição das ouvidorias públicas (COSTA, 1998; SPÍNDOLA, 2012; DE MARIO, 2013). De Mario (2013) destaca que as Ouvidorias são um instrumento democrático voltado para a garantia dos direitos do cidadão e que têm como função principal exercer a interlocução entre o Estado e o Cidadão.

Spíndola (2012) diferencia a ouvidoria de outros canais como o SAC (Serviço de Atendimento ao Cliente), os centros de atendimento chamados de "call center" ou "contact center", e outros assemelhados. A natureza dos serviços e as características do profissional ouvidor são diferentes, a começar pelos tipos de demandas acolhidas e a forma como são tratadas, como é caso de uma demanda de ouvidoria tipificada como denúncia. A Ouvidoria tem por atribuição acolher as manifestações que indiquem falhas, desvios, reclamações e elogios que foram processados ou encaminhados de maneira inadequada pelo SAC (DE MARIO, 2013). Além da denúncia, Spíndola (2012) destaca que a ouvidoria pode receber manifestações que podem ser classificadas em reclamação, sugestão ou elogio.

\section{METODOLOGIA DE PESQUISA}

A pesquisa apresenta inicialmente um caráter exploratório que contempla uma fase qualitativa com o propósito de identificar fatores essenciais percebidos pelos gestores públicos no relacionamento entre a administração pública e os cidadãos no processo de prestação de serviços públicos. A segunda parte possui um enfoque quantitativo correspondendo uma pesquisa conclusiva descritiva para identificar os fatores essenciais percebidos pelos cidadãos que utilizam uma unidade de prestação de serviço público para aprimorar o seu relacionamento com o governo, A pesquisa descritiva conclusiva se 


\section{UM MODELO DE GESTÃO DO RELACIONAMENTO ENTRE OS CIDADÃOS E A ADMINISTRAÇÃO PÚBLICA}

caracteriza pela descrição das características de determinada população, fenômeno ou o estabelecimento de relação entre variáveis. (GIL, 2002; MALHOTRA, 2004)

A fase qualitativa contou com a utilização da metodologia Grounded Theory que foi suportada por uma coleta de dados a partir da realização de entrevistas do tipo semiestruturada por meio de um roteiro. O roteiro foi construído tendo como base o Modelo Unificado de Implantação de CRM (Figura 1).

A Grounded Theory apresenta-se como uma teoria substantiva que surge dos dados analisados, por ser consequência da realidade de um determinado grupo ou situação (VERGARA, 2005; BANDEIRA-DE-MELLO E CUNHA, 2006). Bandeira-de-Mello e Cunha (2006) relatam que a pesquisa que procura utilizar o Grounded Theory como metodologia deve responder as seguintes questões:

- Qual a área substantiva que será pesquisada?

- Quais os sujeitos da pesquisa e o que fazem?

No que se refere à área substantiva, a presente pesquisa procura analisar a gestão de relacionamento com os cidadãos na perspectiva dos gestores. Em relação aos sujeitos da pesquisa e às suas atividades, as entrevistas foram realizadas com 11 gestores estaduais responsáveis diretos pelos quatro canais corporativos de atendimento ao cidadão do Governo do Estado de Minas Gerais (Portal mg.gov.br, a Central de Atendimento Telefônica (LigMinas - 155), as Unidades de Atendimento Integrado (UAIs) e a Ouvidoria Geral do Estado de Minas Gerais), além de gestores de tecnologia da informação da empresa que hospeda as informações geradas por esses canais. As entrevistas foram realizadas nos meses de outubro e novembro de 2013. A análise de conteúdo foi suportada pelo software ATLAS TI versão 7.1.7. O tratamento das entrevistas com os gestores utilizou a análise de conteúdo com base em Bardin (1977) e Vergara (2005).

A fase quantitativa contou com uma pesquisa do tipo survey por meio da aplicação de questionários com os cidadãos que procuraram uma UAI em Belo Horizonte. Com o objetivo de abordar os fatores considerados mais importantes para os cidadãos para aprimorar o relacionamento com o Governo de Minas Gerais, foi elaborado um questionário com 26 variáveis compostas pela escala Likert intervalar de onze pontos que variaram de "Sem importância - Pontuação: 0" até "Extremamente importante - Pontuação: 10" (ZIKMUND E BADIN, 2011).

Este instrumento foi construído com base na revisão da literatura discutida, na pesquisa realizada pelo The Institute for Citizen-Centred Service (2012) e na análise do 


\section{Rodrigo Diniz Lara \& Marlusa de Sevilha Gosling}

conteúdo das entrevistas com os gestores dos canais de atendimento. Além das perguntas relacionadas à percepção, estruturada com base na escala Likert, os participantes também responderam cinco questões voltadas ao levantamento do seu perfil: gênero, faixa etária, nível de escolaridade, ocupação principal e faixa de renda familiar. Um pré-teste do questionário foi realizado com 50 cidadãos que utilizavam a UAI. A partir do pré-teste, as questões foram alteradas ou agrupadas e o questionário finalizado.

Os dados foram coletados com 354 cidadãos que aguardavam a prestação de serviço do Governo de Minas Gerais em uma UAI localizada na cidade de Belo Horizonte. Uma entrevistadora, devidamente treinada, realizou a pesquisa presencialmente no período de 18 de dezembro de 2013 até 30 de dezembro de 2013. Esses dados coletados depois foram repassados para um formulário do Google Docs e, posteriormente, extraídos para uma planilha excel que foi devidamente exportada para o software SPSS (Statistical Package for Social Sciences) 21

Dos 354 questionários coletados, 230 foram considerados válidos após a realização de uma análise outliers univariados, em que se avalia cada variável individualmente, e outliers multivariados, na qual cada caso é avaliado ao longo de um conjunto de variáveis (HAIR EL AL., 2005; 2014). O dimensionamento da amostra foi calculado conforme Hair e colaboradores (2005) que estabelece que a amostra deva ser preferencialmente maior do que 100 para o uso de Análise Fatorial Exploratória e pelo menos cinco vezes mais observações do que o número de variáveis a serem analisadas. Na pesquisa, o número total de indicadores foram 26. Dessa forma, a recomendação da literatura foi seguida tendo em vista que o número mínimo para ser considerada uma amostra válida seriam 130 casos e a amostra válida foi de 230 casos.

A análise das respostas dos cidadãos em relação à survey foi baseada em estatística descritiva e análise fatorial exploratória (AFE) que chegou aos fatores essenciais percebidos pelos cidadãos entrevistados para aprimorar o seu relacionamento com o governo. Essas análises foram suportadas pelos softwares Excel e SPSS 21.

A análise fatorial analisa a estrutura das interrelações entre variáveis distintas para determinar um conjunto de dimensões latentes comuns, tendo como objetivo geral da técnica, resumir a informação de diversas variáveis originais em um conjunto menor de fatores com uma perda mínima de informação (HAIR et al., 2005). O método fatorial de extração utilizado foi o de componentes principais, que conforme Hair e colaboradores (2005) é preferível quando se busca resumir a variância em um número mínimo de fatores. Sobre o método 
UM MODELO DE GESTÃO DO RELACIONAMENTO ENTRE OS CIDADÃOS E A ADMINISTRAÇÃO PÚBLICA

rotacional, que pode ser ortogonal ou oblíquo, optou-se pelo oblíquo, pois possibilita a correlação entre os fatores ao invés de somente fatores independentes (HAIR et al., 2005).

\section{MODELO DE GESTÃO DO RELACIONAMENTO COM O CIDADÃO}

\subsection{Análise qualitativa - A visão dos gestores públicos}

Antes de apresentar aos entrevistados os componentes presentes no Modelo Unificado de Implantação de CRM (Figura 1), foi solicitado aos mesmos que definissem em sua visão qual o conceito de um modelo de gestão de relacionamento com o cidadão. A partir da análise de conteúdo das respostas dessa questão, foi possível criar o esquema utilizando o Atlas TI apresentada na figura 2.

Figura 2 - Conceito de gestão de relacionamento com o cidadão na visão dos gestores

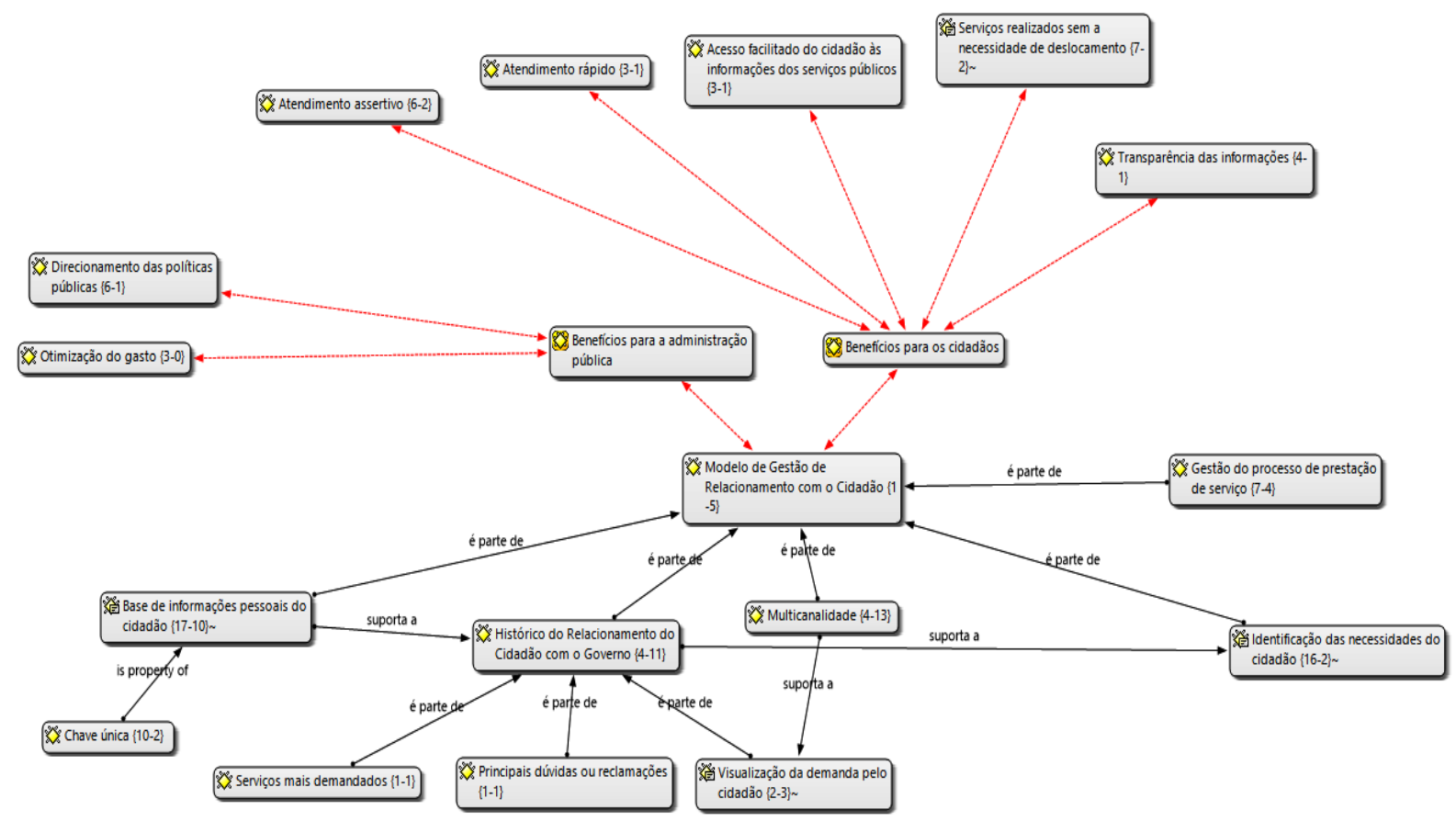

Fonte: Elaborada pelos autores, 2014 


\section{Rodrigo Diniz Lara \& Marlusa de Sevilha Gosling}

A partir da análise da rede " $\mathrm{O}$ conceito de gestão de relacionamento com o cidadão na visão dos gestores", podemos identificar que o modelo pode ser dividido em duas partes: os benefícios trazidos pelo modelo e as partes que compõem o mesmo. Em relação aos benefícios, podemos agrupá-los em duas famílias de códigos, conforme os públicos alvos favorecidos com a implantação do modelo: "Benefícios para os cidadãos" e "Benefícios para a administração pública".

Entre os benefícios esperados para os cidadãos com a implantação do CzRM, um dos códigos mais citados é "Serviços realizados sem a necessidade de deslocamento". Algumas frases dos entrevistados exemplificam esse ponto, como "Quando mais a pessoa iniciar um atendimento pelo telefone ou internet e não precisar se deslocar, você terá um ganho substancial melhor.” (Entrevistado 5); “[...] obter o que quer sem precisar se deslocar. (Entrevistado 9); e "[...] se o cidadão pudesse solicitar a carteira, informar os dados, tocar na tela e um aplicativo fazer a leitura biométrica em tempo real e já conseguir, se for o caso, pagar essa emissão e a entrega pelos correios, seria ótimo, ideal.” (Entrevistado 1). Dunleavy (2005) destaca essa questão como a desintermediação radical que a web possibilita na relação entre governo e cidadãos no sentido de que esses atores podem se conectar diretamente aos sistemas do governo, sem passar pelas unidades físicas.

Na visão de todos os gestores públicos entrevistados, a criação do modelo de gestão de relacionamento com o cidadão $(\mathrm{CzRM})$ tem como sua primeira etapa a definição de uma estratégia governamental. Na área pública, a Constituição Federal já estabelece alguns instrumentos de planejamento de médio e curto prazo como o Plano Plurianual de Ação Governamental (PPA), a Lei de Diretrizes Orçamentárias (LDO) e a Lei Orçamentária Anual (LOA). A definição dessa estratégia governamental suporta a construção de uma política de atendimento ao cidadão no sentido de dar legitimidade a esse processo, assim como a garantia de recursos humanos, financeiros e físicos.

Um componente considerado basilar para a implantação de uma estratégia de CzRM é a construção de uma "Base de informações pessoais do cidadão", que aborde desde dados básicos sobre o mesmo, como informações pessoais e demográficas, até o "Histórico de Relacionamento do cidadão com o governo" que engloba os serviços demandados e as sugestões e reclamações encaminhadas. Esse componente foi o segundo mais citado pelos gestores públicos para a construção de um modelo de CzRM. "O banco é o primeiro passo, primordial [...]", destaca o entrevistado 5. O entrevistado 7 complementa que "[...] o governo 


\section{UM MODELO DE GESTÃO DO RELACIONAMENTO ENTRE OS CIDADÃOS E A ADMINISTRAÇÃO PÚBLICA}

deve tentar reunir ao máximo essas informações de pontos distintos, verificar o grau de confiabilidade e se as informações são dos respectivos cidadãos."

Em seguida à construção dessa "Base de informações pessoais do cidadão", os gestores destacam um processo de gestão da informação que contemple a análise dessas informações para desenvolver e personalizar as ações de relacionamento com o cidadão que serão implantadas. Uma das atividades essenciais decorrentes da gestão da informação é o processo de "Segmentação" dos cidadãos de acordo com as suas necessidades.

O grande fator de destaque da dimensão gestão da informação relatado pela maioria dos entrevistados (entrevistados 1, 2, 3, 5, 6, 7, 8 e 11) é o "Atendimento individualizado". Sigala (2005) coloca que uma implementação de sucesso de marketing de relacionamento depende da coleta e análise das informações do cliente que são utilizadas para desenvolver e personalizar as ofertas. "Não faz sentido eu disponibilizar o serviço da mesma forma para todos os públicos", reforça o gestor 6 . O entrevistado 11 complementa, “[...] tem nichos que precisam de atendimento prioritário ou mesmo de atendimentos diferenciados." "A personalização do atendimento cria um diferencial para o cidadão, e "[...] vai permitir ao governo dar uma atenção mais especializada ao cidadão", aponta o entrevistado 5. Esse código foi citado 23 vezes pelos entrevistados.

No que tange à integração multicanal, o maior benefício visto pelos gestores foi a possibilidade de se ter uma visão única do governo ou do cidadão. Isso significa que, mesmo quando os cidadãos interagirem com mais de um canal de atendimento eles tenham uma visão única do governo e, ao mesmo tempo, o governo tenha uma visão $360^{\circ}$ das demandas do cidadão.

O processo central do modelo de CzRM é a construção dos programas de relacionamento com os cidadãos. A partir da análise das entrevistas dos gestores públicos, foi possível identificar três grandes grupos de programas de relacionamento: acompanhamento da prestação de serviço; programas de recompensas e forma de atendimento apresentados na figura 3. 


\section{Rodrigo Diniz Lara \& Marlusa de Sevilha Gosling}

Figura 3 - Programas de relacionamento com o cidadão na visão dos gestores públicos

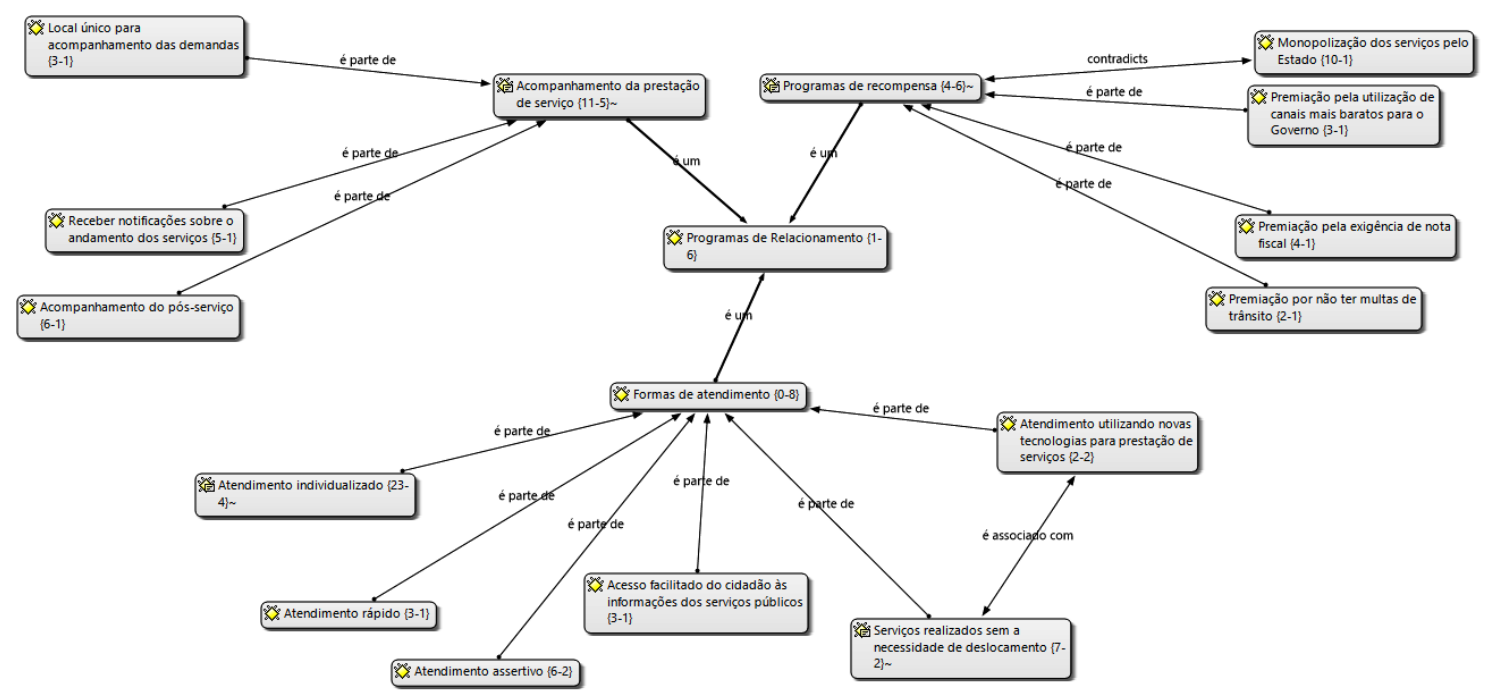

Fonte: Elaborada pelos autores, 2014

A TI é um componente destacado pelos gestores como suporte a toda a implantação de um CzRM. A TI suporta a integração dos canais de atendimento e serviços, a automatização das atividades de atendimento ao cidadão, a consolidação das informações para geração do histórico de relacionamento com o cidadão e a posterior análise estatística dessas informações. Porém, é necessário que a TI estabeleça medidas de segurança que promova a confidencialidade, integridade e disponibilidade dos dados dos cidadãos.

Os gestores destacam a importância da existência de uma estrutura que fique responsável pela implantação do CzRM no governo e tenha apoio da alta gestão, além de corpo técnico e gerencial capacitado. Por fim, os gestores governamentais identificam o processo de avaliação de desempenho como uma atividade-chave para a melhoria contínua do programa de CzRM. Um fator de destaque dentro dessa dimensão é a criação do instituto denominado "Ouvidoria" para recebimento das manifestações dos cidadãos sobre a prestação dos serviços públicos. Os gestores indicaram também alguns indicadores que podem fazer parte desse processo, tais como tempo de atendimento; qualidade do atendimento; índice de satisfação do usuário e índice de conclusividade do atendimento.

\subsection{Análise quantitativa - A visão dos cidadãos}

Em relação à faixa etária, 170 entrevistados (74\%) possuem entre 18 e 45 anos. No que se refere à ocupação profissional dos respondentes, a maior parte está ligada a área de serviços, dividindo-se entre o trabalho no comércio, banco, transporte e hotelaria $(24,35 \%)$ e

REAd | Porto Alegre - Edição 84 - Nº 2 - Maio / Agosto 2016 - p. 333- 362 


\section{UM MODELO DE GESTÃO DO RELACIONAMENTO ENTRE OS CIDADÃOS E A ADMINISTRAÇÃO PÚBLICA}

profissional liberal, professor ou técnico de nível superior $(21,30 \%)$. Em relação ao grau de instrução dos respondentes, aproximadamente metade dos entrevistados (46,96\%) já frequentaram ou frequentam um curso superior. Por fim, em relação à renda mensal familiar, a distribuição entre as faixas de renda "De 1 a 2 salários mínimos", "De 2 a 5 salários mínimos" e "De 5 a 10 salários mínimos" correspondem a mais de $20 \%$ dos entrevistados, cada faixa.

A análise descritiva dos dados envolveu a verificação do desvio padrão e a média de cada um dos indicadores observados. A média das respostas foi considerada alta, variando entre 6,10 ("Disponibilizar um número de telefone único para a prestação de serviço”) a 9,50 ("Ter funcionários que se esforcem para entregar o que você precisava”). Esse resultado de médias altas já era esperado, tendo em vista que os itens apresentados para os cidadãos apresentavam boas práticas para aprimorar o relacionamento com o governo e a escala mensurava o grau de importância. Das cinco variáveis que tiveram maior média quanto ao grau de importância, três estão voltados para os funcionários responsáveis pelo atendimento. Um indicador que também teve alta pontuação foi a privacidade dos dados.

É necessário avaliar a normalidade dos dados para se determinar os testes estatísticos a serem realizados na amostra (Hair et al., 2014). O teste de Kolmogorov-Smirnov foi utilizado por ser indicado para amostras superiores a 50. Com o critério de nível de significância de $1 \%$, todas as variáveis apresentaram significância igual a 0,00 , ou seja, a hipótese nula foi rejeitada. Portanto, a distribuição não é normal em nenhuma das variáveis do estudo.

Para testar a linearidade, calculou-se a correlação linear par a par, utilizando-se a correlação de Spearman. Este método foi utilizado por ser não paramétrico, uma vez que os dados apresentaram ausência de normalidade (Hair et al., 2005). As correlações significativas indicam a presença de dados lineares. Desse modo, 66,74\% dos dados apresentaram correlações significativas no nível de $1 \%$ e 5\%. Finalmente, seguindo os parâmetros indicados por Kline (2011), nenhuma relação excedeu o valor de 0,9, indicando, assim, a ausência de multicolinearidade expressiva entre os itens do questionário.

No intuito de identificar fatores macros que pudessem agrupar as diversas variáveis originais pesquisadas com os cidadãos e facilitar a elaboração de um modelo esquemático de gestão do relacionamento com o cidadão foi adotada a Análise Fatorial Exploratória.

Recomenda-se a exclusão de variáveis que apresentarem baixa comunalidade, isto é, a quantidade total de variância que uma variável compartilhar com todas as outras na análise deve ser superior a 0,4 (Hair et al., 2005). Na AFE realizada com as variáveis independentes, 


\section{Rodrigo Diniz Lara \& Marlusa de Sevilha Gosling}

todas apresentaram comunalidade maior que 0,4. Muthen e Kaplan (1992) destacam que pode ser utilizada a AFE para dados não normais.

No intuito de obter uma estrutura fatorial mais coerente e significativa, optou-se por excluir as variáveis do Quadro 1 que apresentaram as menores cargas fatoriais, abaixo de 0,510, e não mantiveram relação com algum construto específico.

Quadro 1 - Itens excluídos da solução fatorial

\begin{tabular}{ll}
\hline \multicolumn{1}{c}{ Nome da variável } & \multicolumn{1}{c}{ Item correspondente } \\
\hline PESQSATISF & $\begin{array}{l}\text { Realizar pesquisas de satisfação em relação } \\
\text { aos serviços prestados } \\
\text { Proteger o sigilo das suas informações } \\
\text { pessoais }\end{array}$ \\
SIGILOINFORMACOES & $\begin{array}{l}\text { Não pedir dados que você já tenha } \\
\text { informado }\end{array}$ \\
ÑPEDIRDADOS & $\begin{array}{l}\text { Possibilitar que um serviço seja iniciado por } \\
\text { um canal de atendimento (ex: unidade } \\
\text { presencial) e seja finalizado por outro canal } \\
\text { (internet) }\end{array}$ \\
\hline
\end{tabular}

Fonte: Elaborado pelos autores, 2014.

Todos os construtos apresentaram confiabilidade dentro do limite aceitável, superior a 0,6 para o Alfa de Cronbach (Hair et al., 2014), acima de 0,70 para confiabilidade composta (Hair et al., 2014) e 0,45 para validade convergente (Netemeyer, Bearden e Sharma, 2003). A Tabela 1 apresenta os resultados.

Tabela 1 - Critérios de avaliação dos construtos reflexivos quanto à confiabilidade e validade

\begin{tabular}{lccc}
\hline Construto & $\begin{array}{c}\text { Validade } \\
\text { Convergente } \\
\text { (AVE) }\end{array}$ & $\begin{array}{c}\text { Confiabilidade } \\
\text { Composta }\end{array}$ & Alfa de Cronbach \\
\hline ACOMPANHAMENTO & 0,58 & 0,84 & 0,77 \\
CONSOLIDAÇÃO & 0,62 & 0,83 & 0,71 \\
DIVERSIFICAÇÃO & 0,56 & 0,79 & 0,64 \\
FUNCIONÁRIOS & 0,72 & 0,88 & 0,81 \\
RECOMPENSAS & 0,55 & 0,78 & 0,60 \\
FORMA & 0,66 & 0,85 & 0,75 \\
\hline
\end{tabular}

Fonte: Saída do software Smart PLS, 2014

Todos os construtos apresentaram valores de suas cargas cruzadas (indicadores que formam o construto versus o construto) satisfatórios, o que sugere a validade discriminante dos construtos, ou seja, conceitos distintos representam dimensões diferentes, isto é, se os construtos mensuram diferentes aspectos do fenômeno de interesse (Hair et al., 2014). 


\section{UM MODELO DE GESTÃO DO RELACIONAMENTO ENTRE OS CIDADÃOS E A ADMINISTRAÇÃO PÚBLICA}

A estrutura fatorial final foi composta de 6 fatores: Acompanhamento da prestação de serviço; Consolidação dos canais de atendimento; Equipe de atendimento; Forma de atendimento; Recompensas; e Diversificação dos canais de atendimento.

Conforme Hair e colaboradores (2005), as cargas fatoriais de medida 0,30 estariam no nível mínimo; as de medida igual ou superior a 0,40 são importantes e as de 0,50 ou mais são consideradas de significância prática ( $25 \%$ de explicação). Assim, a carga fatorial deve ser superior a 0,70 para que explique 50\% da variância. Cargas acima de 0,80 não são encontradas com frequência nas pesquisas (Hair et al., 2005).

Tabela 2 - Carga fatorial final da Análise Fatorial Exploratória

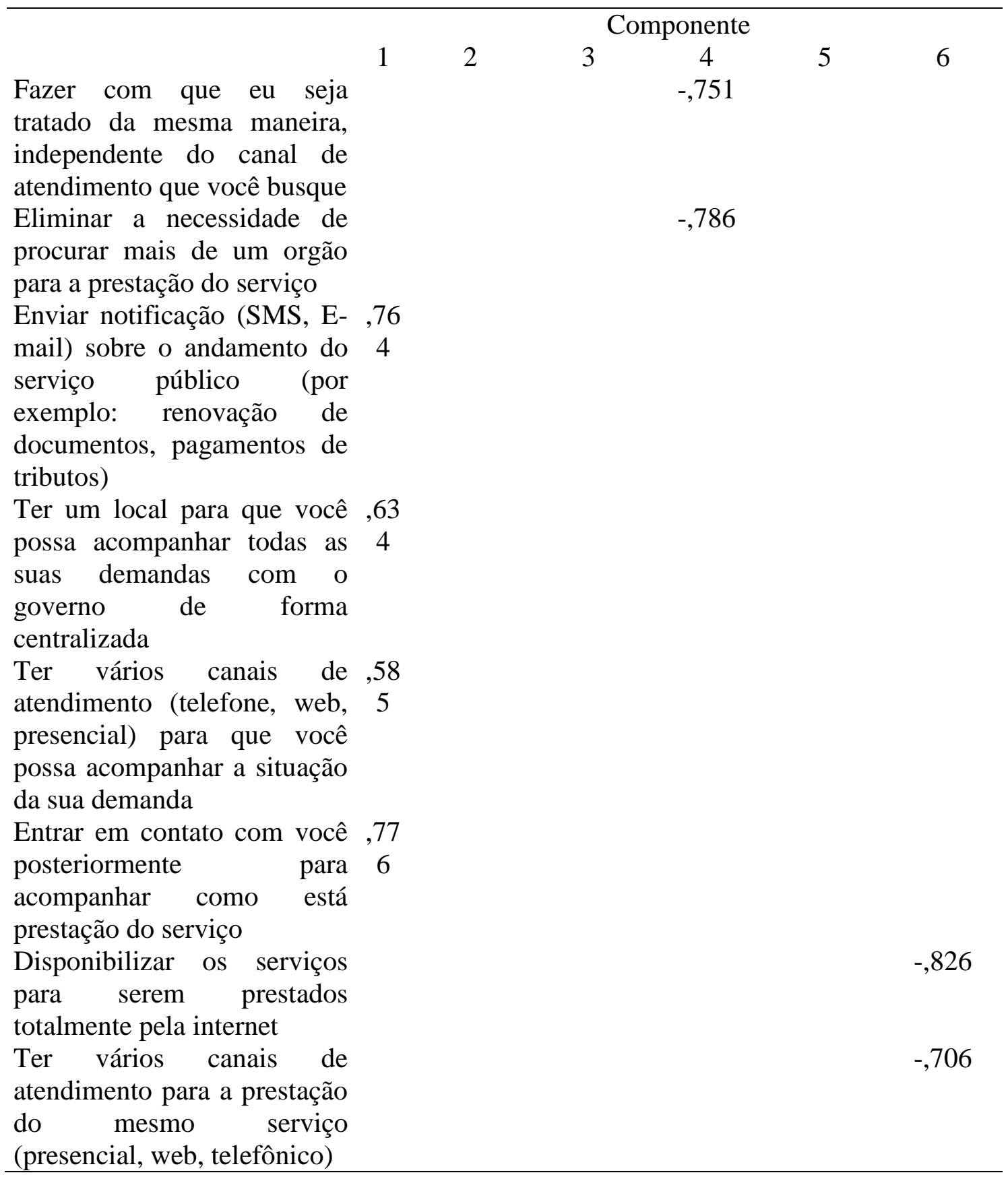

REAd | Porto Alegre - Edição 84 - N 2 - Maio / Agosto 2016 - p. 333- 362 


\begin{tabular}{|c|c|c|c|c|c|}
\hline $\begin{array}{l}\text { Disponibilizar um número de } \\
\text { telefone único para a } \\
\text { prestação de serviço }\end{array}$ & ,833 & & & & \\
\hline $\begin{array}{l}\text { Disponibilizar em um único } \\
\text { local de atendimento vários } \\
\text { serviços públicos }\end{array}$ & ,715 & & & & \\
\hline $\begin{array}{l}\text { Disponibilizar em um único } \\
\text { site da internet todos os } \\
\text { serviços prestados pelo } \\
\text { governo }\end{array}$ & ,797 & & & & \\
\hline $\begin{array}{l}\text { Disponibilizar novas } \\
\text { tecnologias para a prestação } \\
\text { de serviços (redes sociais, } \\
\text { aplicativos para celular) }\end{array}$ & & & & &,- 683 \\
\hline $\begin{array}{l}\text { Fornecer incentivos (ex: } \\
\text { descontos em impostos ou } \\
\text { prêmios) pela utilização de } \\
\text { canais de atendimento mais } \\
\text { baratos para o governo }\end{array}$ & & & & ,782 & \\
\hline $\begin{array}{l}\text { Fornecer incentivos (ex: } \\
\text { descontos em impostos ou } \\
\text { prêmios) pela exigência da } \\
\text { nota fiscal }\end{array}$ & & & & ,603 & \\
\hline $\begin{array}{l}\text { Fornecer incentivos (ex: } \\
\text { descontos em impostos ou } \\
\text { prêmios) por não ter tido } \\
\text { multas de trânsito ao longo } \\
\text { do ano }\end{array}$ & & & & ,745 & \\
\hline $\begin{array}{l}\text { Oferecer um atendimento } \\
\text { individualizado conforme as } \\
\text { minhas necessidades }\end{array}$ & & &,- 707 & & \\
\hline $\begin{array}{l}\text { Ter funcionários que tenham } \\
\text { conhecimentos suficientes } \\
\text { para responder às suas } \\
\text { perguntas }\end{array}$ & & ,795 & & & \\
\hline $\begin{array}{l}\text { Ter funcionários que se } \\
\text { esforcem para entregar o que } \\
\text { você precisava }\end{array}$ & & ,840 & & & \\
\hline $\begin{array}{lll}\text { Ter funcionários } & \text { que } \\
\text { inspirem confiança } & \text { aos } \\
\text { cidadãos } & & \\
\end{array}$ & & ,857 & & & \\
\hline
\end{tabular}

Fonte: Saída do SPSS, 2014.

Notas:

(1) Método de extração: Análise do Componente principal.

(2) Método de rotação: Oblimin com normalização de Kaiser. 


\section{UM MODELO DE GESTÃO DO RELACIONAMENTO ENTRE OS CIDADÃOS E A} ADMINISTRAÇÃO PÚBLICA

\subsubsection{Acompanhamento da prestação de serviço}

O primeiro fator denominado "Acompanhamento da prestação de serviço" também foi identificado a partir das entrevistas com os gestores públicos e possui variáveis que apresentam como os cidadãos podem acompanhar as suas demandas em relação aos serviços prestados pelo governo. Aponta-se também a importância do governo manter o cidadão constantemente informado sobre o andamento das etapas de prestação de serviço público.

\subsubsection{Consolidação dos canais de atendimento}

O segundo fator identificado foi a "Consolidação dos canais de atendimento", como telefone, portal e unidade de atendimentos únicos. Existe uma tendência dos governos consolidarem os seus tipos de canais em apenas uma plataforma para facilitar o acesso dos cidadãos. Saremi (2009) destaca que essa consolidação dos canais é um dos facilitadores da implementação futura da integração multicanal; já que o processo de integração de um número menor de canais facilita essa iniciativa.

\subsubsection{Funcionários de atendimento}

O terceiro fator foi denominado "Funcionários de atendimento". Essa dimensão, com as suas devidas subdivisões, geralmente é utilizada em pesquisa de qualidade de serviços como a SERVQUAL (Parasuramn, Zeithaml e Berry, 1988). As variáveis tratadas nesse fator envolvem o conhecimento, a capacidade de transmitir confiança e de resolução das necessidades dos cidadãos pelos funcionários que realizam o atendimento.

\subsubsection{Forma de atendimento}

O quarto fator "Forma de atendimento" contempla formas do governo atender ao cidadão como o atendimento individualizado ou personalizado, que é citado por vários autores que trabalham o marketing de relacionamento (Sin, Tse e Yim, 2005; Yamashita, 2006; KANNABIRAN, XAVIER E ANANTHARAAJ, 2004; Schellong, 2008), além de uma ação muito citada pelos gestores na fase qualitativa da pesquisa. 


\section{Rodrigo Diniz Lara \& Marlusa de Sevilha Gosling}

\subsubsection{Recompensas}

A área privada tem adotado ao longo dos últimos anos programas de recompensas para incentivar o cliente a aumentar o seu consumo usual. No caso do governo, a partir da análise das entrevistas com os gestores e dos resultados da pesquisa da The Institute for Citizen-Centred Service (2012), foram identificados itens que forma o fator "Recompensas que podem ser oferecidos aos cidadãos como medida para incentivar a prática de alguma ação que seja importante e tenha retorno financeiro ou social para o governo.

\subsubsection{Diversificação dos canais de atendimento}

O fator "Diversificação dos canais de atendimento" é um componente também identificado por Schellong (2008) e Reddick (2011) no sentido de que os governos devem fornecer informações e serviços ao público por meio de múltiplos canais de serviços, principalmente incentivando a utilização das novas tecnologias da informação (Dunleavy, 2005) . Tal fator não pode ser trabalhado de forma desalinhada com as premissas da integração multicanal de visão única do governo pelo cidadão e do cidadão pelo governo.

\subsection{Modelo Esquemático de Gestão de Relacionamento com o Cidadão}

Tendo em vista as ponderações acima, e com o objetivo de aprimorar a relação do governo com o cidadão no que tange à prestação de serviços públicos, propõem-se um Modelo Esquemático de Gestão de Relacionamento com o Cidadão (Figura 4), contemplando uma análise dos principais fatores identificados pelos gestores públicos e pelos cidadãos que participaram da pesquisa, além dos modelos conceituais de implantação de CRM estudados nesse artigo.

A partir da interpretação das entrevistas com os gestores públicos foi possível identificar alinhamento com os conceitos apresentados pelos modelos teóricos de implantação de CRM. Dessa forma, um modelo para aprimorar a gestão do relacionamento com o cliente ou cidadão passa por componentes comuns como a estratégia, estrutura, gestão da informação, tecnologia da informação, integração multicanal, programas de relacionamento e avaliação de desempenho. 


\section{UM MODELO DE GESTÃO DO RELACIONAMENTO ENTRE OS CIDADÃOS E A ADMINISTRAÇÃO PÚBLICA}

É importante destacar que dentro de cada componente existe uma adaptação para o contexto público, como no aspecto da estratégia que leva em consideração os instrumentos de planejamento governamental como PPAG e LOA. Entretanto, são adaptações pontuais e a estrutura do modelo é semelhante ao CRM.

Para que o modelo de CzRM tenha uma estrutura robusta, a visão dos cidadãos foi contemplada no modelo. Dessa forma, por meio da análise fatorial exploratória foi possível incorporar ao modelo os fatores que na visão dos cidadãos são essenciais para aprimorar o seu relacionamento com o governo: Acompanhamento da prestação de serviço; Consolidação dos canais de atendimento; Forma de atendimento; Recompensas; Diversificação dos canais de atendimento.

Figura 4 - Modelo Esquemático de Gestão de Relacionamento com o Cidadão

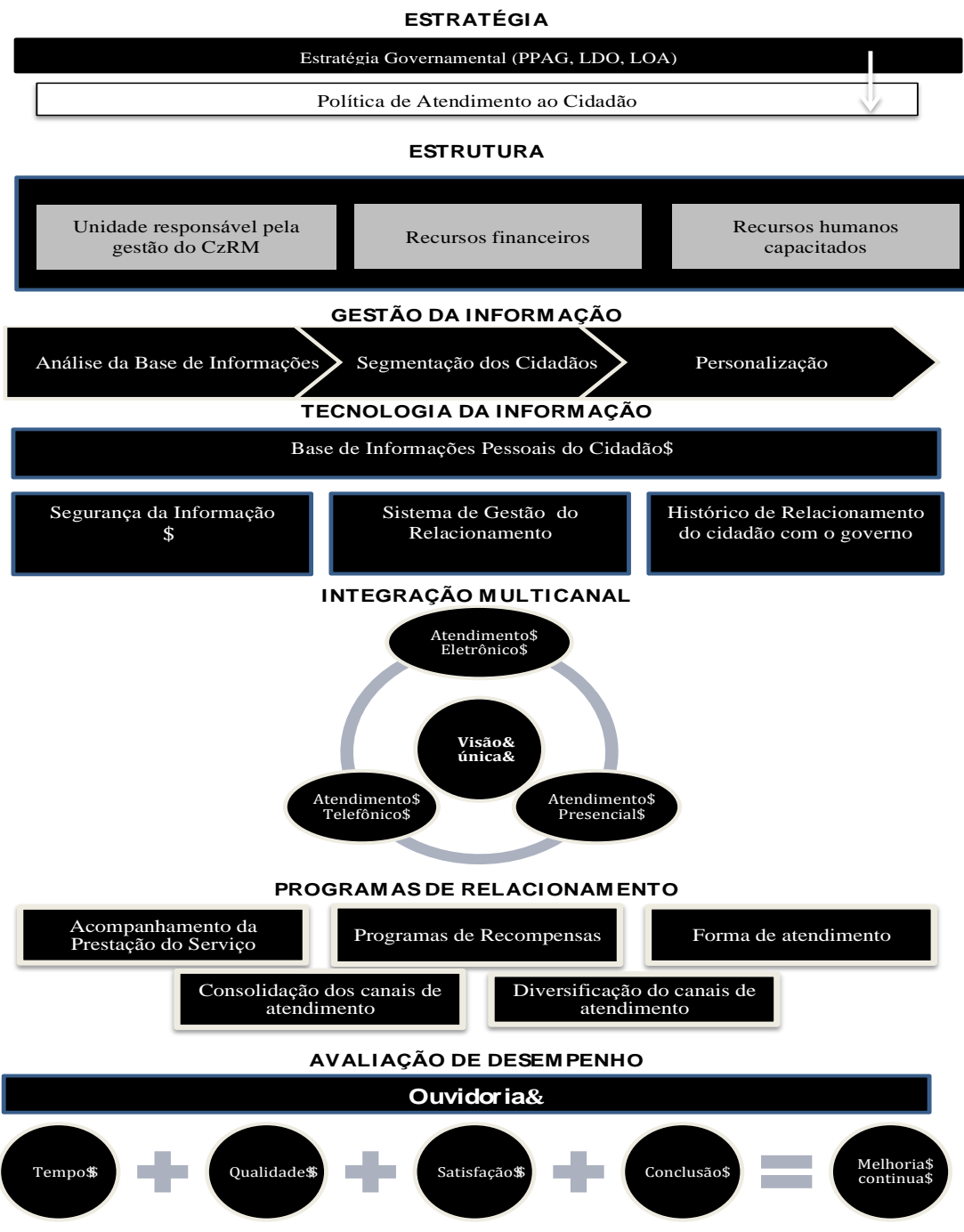

Fonte: Elaborado pelos autores, 2014. 


\section{Rodrigo Diniz Lara \& Marlusa de Sevilha Gosling}

\section{CONSIDERAÇÕES FINAIS}

A reforma gerencial da administração pública possui como um dos seus principais debates a discussão do papel do cidadão como cliente na prestação de serviços públicos. A importação do termo cliente da administração privada constitui um progresso também para a cidadania, pois a orientação para o cliente significa atender às suas necessidades e respeitá-lo. Porém, o conceito de cidadão-cliente ainda apresenta princípios de mercado pouco ajustados à área pública.

A administração pública voltada para o cidadão pode ser definida como um modelo gerencial cujo propósito é oferecer serviços públicos de maior qualidade, atendendo melhor às demandas dos seus usuários. Os cidadãos são também portadores de direitos e deveres e, rotineiramente, não podem escolher um serviço alternativo, caso estejam insatisfeitos com o serviço prestado pelo setor público. Nesse sentido, a mudança na administração pública necessita não apenas de alterações estruturais, de regras e processos, mas também, e principalmente, de intervenção para criar uma nova cultura organizacional de comprometimento com a prestação de serviços de qualidade para o cidadão.

A área pública e o setor privado possuem divergências e convergências no que se refere ao contexto, diretrizes e objetivos da implantação da Gestão do Relacionamento com os Cidadãos (CzRM) e Gestão do Relacionamento com os Clientes (CRM), respectivamente. Em função destas diferenças e semelhanças, a pesquisa procurou identificar na visão dos gestores públicos e dos cidadãos quais conceitos, métodos e ferramentas principais do CRM são capazes de apoiar adequadamente o CzRM e descartar aquelas que não são aderentes à gestão pública. A pesquisa gerou um modelo esquemático com sete componentes principais para implantação da gestão de relacionamento com os cidadãos para melhorar a relação entre os cidadãos e a administração pública no que tange à prestação de serviços públicos. Os componentes são:

1. Estratégia: componente considerado como o início do processo para implementação da do CzRM. Estabelece as premissas para o desenvolvimento dos outros componentes. Deve contar com a estratégia do governo e ser desdobrado na política de atendimento ao cidadão.

2. Estrutura: responsável pela implantação e manutenção do CzRM no governo. Deve contar com equipe técnica e gerencial capacitada, além de recursos financeiros e apoio da alta gestão para implantar programas de relacionamento com os cidadãos;

REAd | Porto Alegre - Edição 84 - N 2 - Maio / Agosto 2016 - p. 333- 362 


\section{UM MODELO DE GESTÃO DO RELACIONAMENTO ENTRE OS CIDADÃOS E A} ADMINISTRAÇÃO PÚBLICA

3. Gestão da informação: envolve o uso intensivo das informações dos cidadãos e da sua relação com o governo, no sentido de desenvolver e personalizar ações de prestação de serviços públicos conforme as necessidades dos públicos-alvo, identificados a partir do processo de segmentação;

4. Tecnologia da Informação: componente que suporta as atividades do CzRM, com destaque para a construção de uma base de dados que permita a gestão integrada das informações originadas pelos sistemas de informação, sob o ponto de vista do cidadão. Aspecto central em relação à TI é o estabelecimento de medidas de segurança que promovam a confidencialidade, integridade e disponibilidade dos dados dos cidadãos.

5. Integração multicanal: que tem como objetivo principal permitir que o cidadão tenha uma visão única do governo por meio da integração dos canais de atendimento. Esse integração possibilita também que o governo tenha uma visão total sobre as demandas de um mesmo cidadão.

6. Programas de relacionamento: principal entrega de um modelo de CzRM no sentido de aprimorar a relação entre o governo e os cidadãos, a pesquisa identificou cinco grandes grupos na percepção dos gestores e cidadãos: acompanhamento da prestação de serviço; programa de recompensas; forma de atendimento; funcionários de atendimento; consolidação dos canais de atendimento; e diversificação dos canais de atendimento.

7. Avaliação de desempenho: componente responsável por fornecer informações para melhoria contínua do modelo. Componente central nesse processo é a criação de uma Ouvidoria para receber reclamações, sugestões e elogios do cidadão sobre a prestação do serviço. Esse processo também é alimentado por indicadores como tempo, qualidade, conclusividade e satisfação do atendimento prestado ao cidadão.

Sobre as limitações dos métodos adotados, as respostas dos entrevistados não podem ser generalizadas, apesar de terem contribuído para uma visão mais holística do caso estudado. Além disso, o pesquisador pode ter incorporado vieses não intencionais às análises das entrevistas e dos dados.

A seguir, é apresentada uma lista não exaustiva de estudos para aprofundamento.

a) Emprego de amostra mais volumosa e ampla com os cidadãos que utilizam serviços públicos de outros governos municipais e estaduais permitindo a generalização dos resultados e comparação entre regiões e esferas de governo diferentes; 


\section{Rodrigo Diniz Lara \& Marlusa de Sevilha Gosling}

b) Realização de pesquisas com cidadãos que utilizem outros canais de atendimento, como o call center e os portais governamentais para identificar fatores que aprimoram o relacionamento;

c) Ampliação das entrevistas semiestruturadas da fase qualitativa para os gestores dos órgãos e entidades que utilizam os canais de atendimento corporativos para a captura de quantidade mais expressiva de indicadores de relacionamento com o cidadão para a consolidação dos construtos relacionados ou criação de novos construtos.

Em meio à importância cada vez maior da administração pública aprimorar o seu relacionamento com o cidadão por meio da excelência no serviço público, na certeza de que modelos são reducionistas e métodos sempre apresentam limitações, espera-se, que a pesquisa tenha contribuído para ampliar a discussão sobre o tema proposto.

\section{REFERÊNCIAS BIBLIOGRÁFICAS}

ABRUCIO, Luiz F. O impacto do modelo gerencial na administração pública: um breve estudo sobre a experiência internacional recente. Brasília: ENAP, 1997 (Cadernos ENAP, no 10) Disponível em: <http://www.bresserpereira.org.br/Documents/MARE/TerceirosPapers/96-Abrucio,Fernando.pdf > Acessado em 01/06/12.

BANDEIRA-DE-MELLO, Rodrigo; CUNHA, Cristiano J. C. A. Grounded Theory. In: GODOI, Christiane; BANDEIRA-DE-MELLO, Rodrigo; SILVA, Anielson B. Pesquisa Qualitativa em Organizações: Paradigmas, Estratégias e Métodos. São Paulo: Ed. Saraiva, 2006.

BARDIN, Laurence. Análise de Conteúdo. Lisboa: Edições 70, 1977.

BARZELAY, M. The new public management: a bibliographical essay for Latin American (and other) scholars. International public management journal, v. 3, p. 229-265, 2000.

BRASIL. Ministério da Administração Federal e Reforma do Estado. Plano diretor da reforma do aparelho do estado. Brasília, 1995. Disponível em:

<http://www.bresserpereira.org.br/view.asp?cod=121> Acessado em 10/06/12.

BRESSER-PEREIRA, Luiz C. Da administração pública burocrática à gerencial. In:

BRESSER-PEREIRA, Luiz C; SPINK; Peter (Coord.). Reforma do Estado e Administração Pública Gerencial, Rio de Janeiro: FGV, 2006.

BRESSER-PEREIRA. Reflexões sobre a reforma gerencial brasileira de 1995. Revista do Serviço Público, 50(4), p. 5-30, 1999.

COSTA, Frederico L. da. A ouvidoria como instrumento para a efetividade da ação pública e a promoção da cidadania. RAP, v. 32. n.1, p. 163-170, jan/fev, 1998. 


\section{UM MODELO DE GESTÃO DO RELACIONAMENTO ENTRE OS CIDADÃOS E A} ADMINISTRAÇÃO PÚBLICA

DE MARIO, Camila Gonçalves. Ouvidorias Públicas em Debate: possibilidades e desafios. DE MARIO, Camila Gonçalves (org.) - 1. ed. - eBook - Jundiaí, SP: Paco Editorial, 2013.

DEMO, Gisele; PONTE, Valter. Marketing de Relacionamento (CRM): estado da arte e estudo de casos. São Paulo: Atlas, 2008.

DUNLEAVY, Patrick. New public management is dead - long live digital-era governance. Journal of Public Administration Research and Theory, p. 467-494, Set, 2005.

GIL, Antônio. C. Como elaborar projetos de pesquisa. 4. ed. São Paulo: Atlas, 2002. 176 p.

GUMMENSSON, Evert. Marketing de relacionamento total: gerenciamento de marketing, estratégias de relacionamento e abordagem de CRM para economias de rede. 2. ed. Porto Alegre: Bookman, 2005.

HAIR, Joseph F. Jr. et al. Análise Multivariada de Dados. Porto Alegre: Bookman, 5. Ed., 2005.

HAIR, Joseph F. Jr. et al. A Primer on Partial Least Squares Structural Equation Modeling (PLS-SEM). Los Angeles: Sage Publications, 2014.

HOOD, C. The "new public management" in the 1980s: variations on a theme. Accounting, Organizations and Society, v. 20, n. 2/3, p. 93-109, 1995.

KANNABIRAN, Ganesan; XAVIER, M, J; ANANTHARAAJ, Ammu. Enabling egovernance through citizen relationship management-concept, model and applications. Journal of Marketing. Vol. 69. p. 223-240, Out, 2004.

MALHOTRA, Naresh K. Pesquisa de Marketing: Uma Orientação Aplicada. (5.ed.) Porto Alegre: Bookman, 2004.

NETEMEYER, Richard G.; BEARDEN, W.O.; SHARMA, Subhash. Scaling procedures: issues and applications. Thousand Oaks, CA: Sage, 2003.

OSBORNE, D; GAEBLER, T. Reinventing government: how the entrepreneurial spirit is transforming the public sector. Reading, MA: Addison-Wesley, 1992.

PAES DE PAULA, A, P. Por uma nova gestão pública: limites e potencialidades da experiência contemporânea. Rio de Janeiro: FGV, 2005. 201 p.

PARASURAMAN, A., ZEITHAML, Valarie A.; BERRY, Leonard L. SERVQUAL: A Multiple-Item Scale for Measuring Consumer Peceptions of Service Quality. Journal of Retailing, New York: New York University, Spring 1988. p.12-40.

PAYNE, Adrian. Handbook of CRM: achieving excellence in customer management. Oxford: Elservier, 2005. 438 p. 


\section{Rodrigo Diniz Lara \& Marlusa de Sevilha Gosling}

PAYNE, Adrian; FROW, Pennie. A strategic framework for customer relationship management. Journal of Marketing. Vol. 69. p. 167-176, October, 2005.

PECI, A.; PIERANTI, O. P.; RODRIGUES, S. Governança e new public management: convergências e contradições no contexto brasileiro. Organizações \& Sociedade, v.15, n.46, Jul/Set, p. 39-55, 2008.

PRATA, C. M. As várias faces da relação cidadão x estado: antigos papéis e novas metáforas. In: ENCONTRO ANUAL DA ASSOCIAÇÃO NACIONAL DE PÓS-GRADUAÇÃO E PESQUISA EM ADMINISTRAÇÃO, 22., 1998, Foz do Iguaçu. Anais... Foz do Iguaçú/PR: ANPAD, 1998.

REDDICK, Christopher G. Customer relationship management (CRM) technology and organisational change: evidence for the bureaucratic and e-government paradigms.

Government Information Quarterly, 2011, Vol 28, pp. 346-353.

SAREMI, Mohammad S. Critical Success Factors in Citizen Relationship Management. 2009. 134 p. Dissertação (Mestrado em Marketing e e-commerce) - Department of Business Administration and Social Sciences. Luleå University Technology. Luleå, 2009.

SCHELLONG, Alexander; LANGENBERG, Thomas. Managing Citizen Relationships in Disasters: Hurricane Wilma, 311 and Miami-Dade County. System Sciences, HICSS 2007, 2007

SCHELLONG, Alexander. Citizen Relationship Management: a study of CRM in Government. European University Studies: Frankfurt, 2008.

SECCHI, L. Modelos organizacionais e reformas da administração pública. Rev. Adm. Pública, Rio de Janeiro, v. 43, n. 2, Apr. 2009.

SHETH, Jagdish N; PARVATIYAR, Atul The domain and Conceptual Foundations of Relationship Marketing. IN: SHETH, Jagdish, N; PARVATIYAR, Atul. Handbook of Relationship Marketing. Thousand Oaks: Sage, 2000.

SIGALA, Marianna. Integrating customer relationship management in hotel operations: managerial and operations implications. International Journal of Hospitality Management, $\mathrm{n}$. 24, p. 391-413, 2005.

SPÍNDOLA, José F. O Instituto da Ouvidoria como ferramenta para a melhoria da gestão pública: experiência do METROREC e DETRAN-PE. 2012. 136 f. Dissertação (Mestrado em Administração Pública) - Escola Brasileira de Administração Pública e de Empresas, Fundação Getúlio Vargas, São Paulo, 2012.

THE INSTITUTE FOR CITIZEN-CENTRED SERVICE. Citizen First 6. Canadá, 2012.

VERGARA, Sylvia C. Métodos de Pesquisa em Administração. São Paulo: Atlas, 2005. 287 p. 
UM MODELO DE GESTÃO DO RELACIONAMENTO ENTRE OS CIDADÃOS E A ADMINISTRAÇÃO PÚBLICA

VIGODA, Eran. From responsiveness to collaboration: Governance, citizens, and the next generation of public administration. Public Administration Review, 2002.

WINER, Russel. A Framework for Customer Relationship Management. California Management Review, 43, Summer, p. 89-105.2001.

YAMASHITA, Elaine C. Gestão do Relacionamento com os Cidadãos: a Administração Pública com foco no cidadão e suas influências sobre a participação no processo democrático. 2003. 155 p. Dissertação (Mestrado em Engenharia de Produção) - COPPE, Universidade Federal do Rio de Janeiro, Rio de Janeiro, 2003. Disponível em:

<http://biblioteca.gpi.ufrj.br/xmlui/handle/1/271> Acessado em 02/02/12.

ZIKMUND, William; BADIN, Barry J. Princípios da Pesquisa de Marketing. São Paulo: Cengage Learning, 2011. 